ARTICLE

https://doi.org/10.1038/s41467-019-10937-z

\title{
Provenance of uranium particulate contained within Fukushima Daiichi Nuclear Power Plant Unit 1 ejecta material
}

\author{
Peter G. Martin (1) 1, Marion Louvel ${ }^{2}$, Silvia Cipiccia ${ }^{3}$, Christopher P. Jones (1) 1, Darren J. Batey ${ }^{3}$, \\ Keith R. Hallam (1) ${ }^{1}$, Ian A.X. Yang ${ }^{1}$, Yukihiko Satou ${ }^{4}$, Christoph Rau ${ }^{3}$, J. Fred W. Mosselmans (D) ${ }^{3}$, \\ David A. Richards (D) ${ }^{5} \&$ Thomas B. Scott ${ }^{1}$
}

Here we report the results of multiple analytical techniques on sub-mm particulate material derived from Unit 1 of the Fukushima Daiichi Nuclear Power Plant to provide a better understanding of the events that occurred and the environmental legacy. Through combined $x$-ray fluorescence and absorption contrast micro-focused $x$-ray tomography, entrapped $U$ particulate are observed to exist around the exterior circumference of the highly porous Si-based particle. Further synchrotron radiation analysis of a number of these entrapped particles shows them to exist as $\mathrm{UO}_{2}$-identical to reactor fuel, with confirmation of their nuclear origin shown via mass spectrometry analysis. While unlikely to represent an environmental or health hazard, such assertions would likely change should break-up of the Si-containing bulk particle occur. However, more important to the long-term decommissioning of the reactors at the FDNPP (and environmental clean-upon), is the knowledge that core integrity of reactor Unit 1 was compromised with nuclear material existing outside of the reactors primary containment.

\footnotetext{
${ }^{1}$ Interface Analysis Centre, School of Physics, HH Wills Physics Laboratory, University of Bristol, Bristol BS8 1TL, UK. ${ }^{2}$ Department of Earth Sciences, University of Cambridge, Bullard Laboratories, Madingley Road, Cambridge CB3 OEZ, UK. ${ }^{3}$ Diamond Light Source, Harwell Science and Innovation Park, Didcot, OX OX11 ODE, UK. ${ }^{4}$ Collaborative Laboratories for Advanced Decommissioning Science, Japan Atomic Energy Agency, Tomioka-Machi, Futaba-gun, Fukushima 979-1151, Japan. ${ }^{5}$ School of Geographical Sciences, University of Bristol, Bristol BS8 1SS, UK. Correspondence and requests for materials should be addressed to P.G.M. (email: peter.martin@bristol.ac.uk)
} 
ir-fall material derived from the Fukushima Daiichi Nuclear Power Plant (FDNPP) accident has formerly been isolated and analyzed from localities across Japan, extending hundreds of kilometers away from the facility ${ }^{1-4}$. In contrast to the smaller and highly spherical fallout particles observed at greater distances from the accident site, larger particulates extracted from bulk sediment material sourced from close to the facility with a complex exterior form ${ }^{5,6}$ here we reveal new insight into the accident conditions.

Following the March 2011 accident and radioactivity release, core inventory modeling using the ORIGEN source-code ${ }^{7}$ attributed specific radiocesium $\left(\mathrm{Cs}^{\star}\right)$ activity and atomic (isotope) ratios to each of the sites of three operational reactor Units $(1,2$, and 3 ) and spent fuel storage ponds $(1,2,3 \text {, and } 4)^{8}$. These characteristic ratios arise due to the contrasting half-lives of the fission product isotopes $-{ }^{137} \mathrm{Cs}\left(t_{1 / 2}=30.17\right.$ years $)$ and ${ }^{134} \mathrm{Cs}\left(t_{1 /}\right.$ ${ }_{2}=2.065$ years $)^{9}$, and also as a consequence of the differing levels of burn-up of the fuel at each of these localities. Nishihara et al. ${ }^{8}$ attributed a ${ }^{134} \mathrm{Cs} /{ }^{137} \mathrm{Cs}$ activity ratio $>1.0$ to material derived from reactor Units 2 and 3 (1.08 and 1.04, respectively) and values $<1.0(0.94)$ to that from reactor Unit 1 . Resulting from the decay of the shorter-lived ${ }^{134} \mathrm{Cs}$, activity values from the spent fuel ponds, in contrast, were $<1.0$ (Unit 1: 0.54, Unit 2: 0.64 , Unit 3: 0.74 , and the most heavily loaded, Unit $4: 0.68$ ).

Unlike the major north-west trending fallout plume (the source of the majority of the land-ward contamination) that has been shown to exhibit the characteristic $\mathrm{Cs}^{\star}$ signature of reactor Unit $2^{10-12}$, the Unit 1 release is of limited spatial extent. This contrasts with having not been released following the large-scale reactor building hydrogen explosions observed at Units 1 and $3^{13}$, but a believed breach in the structural integrity of the primary containment vessel (PCV) on the 15 March 2011 (following extensive, later inspections) ${ }^{13-15}$.

Alongside wide-area mapping and monitoring studies, singleparticle analysis has confirmed that the individual fine-scale radioactive material sourced from the region to the north-west of the plant also exhibited a $\mathrm{Cs}^{\star}$ ratio attributable to the FNDPP Unit $2^{16}$. Owing to its widespread environmental dispersion, this particulate has been the subject of the majority of the Fukushima nuclear forensics studies undertaken thus far. Defined in the initial scanning electron microscopy (SEM) and energy-dispersive spectroscopy (EDS) particulate analysis of Adachi et al. ${ }^{2}$ as Csballs, these highly spherical and Si-based particles were collected by high-volume aerosol sampling in Tsukuba, $170 \mathrm{~km} \mathrm{SW}$ of FDNPP. Kogure et al. ${ }^{17}$, conduce these Cs-balls to be formed by atmospheric condensation (around solid nucleation sites), however, attempts to reproduce such glassy particles has proved unsuccessful, which led the authors to suggest that the microparticles were formed in highly specific conditions in the nuclear reactor environment. Subsequent synchrotron analysis of the same particulate by Abe et al. ${ }^{1}$, revealed the occurrence of $U$, in the center of a numbers of these particles-each of which averaged $2.1 \mu \mathrm{m}$ in diameter. Further studies have extended the analysis of such micron-scale, reactor Unit 2-derived particulate through the application of destructive techniques, including transmission electron microscopy (TEM) following focused ion beam (FIB) sectioning to examine the interior structure and composition of the samples $3,4,17,18$.

Here we focus on the much larger diameter $(>100 \mu \mathrm{m})$ and considerably more angular particulates collected much closer to the FDNPP $3,5,16$, which possess a lower ${ }^{134} \mathrm{Cs} /{ }^{137} \mathrm{Cs}$ activity ratio of $<1.0$ and are therefore ascribed the radioactive release from reactor Unit 1 (occurring earlier on the 12 March 2011, associated with the reactor-building hydrogen explosion ${ }^{13-15}$ ). The contamination (and particulate) was deposited within a plume to the north-north-west/north of the Fukushima site-trending towards the nearby city of Minamisoma-consistent with the prevailing wind conditions and directions at the time of the release $\mathrm{e}^{19,20}$. In addition to the contrasting release mechanisms, the main $60 \mathrm{~km}$ long (Unit 2) contamination plume was the result of wet deposition caused by coincident rainfall events-whereas the plume from Unit 1 was deposited under dry conditions ${ }^{21,22}$. Corroboration of the spatially contrasting ${ }^{134} \mathrm{Cs} /{ }^{137} \mathrm{Cs}$ activity ratios around the FDNPP has been detailed in the work of Nishizawa et al. ${ }^{11}$

The larger particulates have received sparse attention compared to the Unit 2 particulate, perhaps, because it has been found closer to the FDNPP site $(<5 \mathrm{~km})$, where people will not return to reside for a considerable period of time ${ }^{23}$. This Unit 1 material was first identified and isolated by Satou ${ }^{16}$ who identified a mean particle diameter $>100 \mu \mathrm{m}$ and a lower activity (Bq) per particle volume $\left(\mu \mathrm{m}^{3}\right)\left(1.0 \times 10^{5} \times[\text { volume }]^{0.39}\right)$ than Unit 2derived material $\left(2.0 \times 10^{16} \times \text { [volume }^{1.40}\right)^{24}$. Initial synchrotron characterization of this material, comparing its composition to the smaller Cs-balls was undertaken by Ono et al. ${ }^{6}$. Within this work, on a small $75 \mu \mathrm{m} \times 75 \mu \mathrm{m}$ spherical portion of an elongate sub-mm particle, a highly heterogeneous (including $\mathrm{Mo}, \mathrm{Fe}, \mathrm{Ni}$, $\mathrm{Cd}, \mathrm{Sn}$, and $\mathrm{Cr}$ ) distribution of elemental constituents was identified alongside the existence of $U$ in addition to other elements concentrated around its surface. Additional analysis of Unit 1 particulate suggests that the bulk of the sub-mm particle results from the melting and amalgamation of fibrous (Si-based) Rockwool $^{\mathrm{TM}}$ thermal insulation material under the intense heat following the loss of coolant incident (LOCI) ${ }^{24}$.

This work seeks to determine if these inclusions (that have same length-scale as the $U$ particulate contained within the highly spherical Unit 2 particulate ${ }^{1}$ ), are of actinide composition and if so, whether they can be unequivocally sourced to Unit 1 at the FDNPP. The means of attributing the $U$ to specific FDNPP reactors relies on contrasting ${ }^{235} \mathrm{U}$-enrichment levels contained in the different reactors fuel assemblies. While reactor Units 2 and 3 contained fuel with $3.8 \mathrm{wt} \%{ }^{235} \mathrm{U}$ (greater than the $0.7 \mathrm{wt} \%{ }^{235} \mathrm{U}$ of natural $U$ ), the fuel of Unit 1 was constituted by ${ }^{235} \mathrm{U}$ concentrations of between 3.4 and $3.6 \mathrm{wt} \%{ }^{25}$.

\section{Results}

Fluorescence tomography. Rendering of the $U$ signal derived from synchrotron radiation micro-X-ray fluorescence (SR- $\mu$-XRF) applied to a series of $2.5 \mu \mathrm{m}$ thickness slices obtained following the synchrotron radiation micro-X-ray tomography (SR- $\mu$-XRT) analysis are shown in Fig. 1. As a result of the earlier compositional analysis performed on this material, the locations of Fe-rich and cement fragments contained within this material are also shown. From these two-dimensional reconstructions, the U particulate is observed to be near-exclusively associated with the exterior circumference of the particle-occurring at depths averaging $10 \mu \mathrm{m}$ into the highly porous Si-based matrix. While the $\mathrm{U}$ particulate appears to possess a highly rounded form (owing to the $5.0 \mu \mathrm{m}$ diameter round beam profile and resulting $2.5 \mu \mathrm{m}$ step size of the XRF measurements) the size and spherical shape is likely to represent an exaggeration of its true size and a greater degree of rounding than its true form.

We note that one $U$ particle is found not on the particulates exterior, but rather within the sub-mm CF-01 sample. This particle (highlighted in Fig. $1 \mathrm{~g}-22.5 \mu \mathrm{m}$ thickness section) is conversely enclosed by several spherical voids (that together constitute $24 \%$ of the particle's total internal pore volume), in addition to being closely associated with the highlighted $\mathrm{Fe}$ and cement composition fragments. Following the earlier examination of this ejecta material, such a high-energy release scenario is believed to have embedded these reactor-sourced structural 

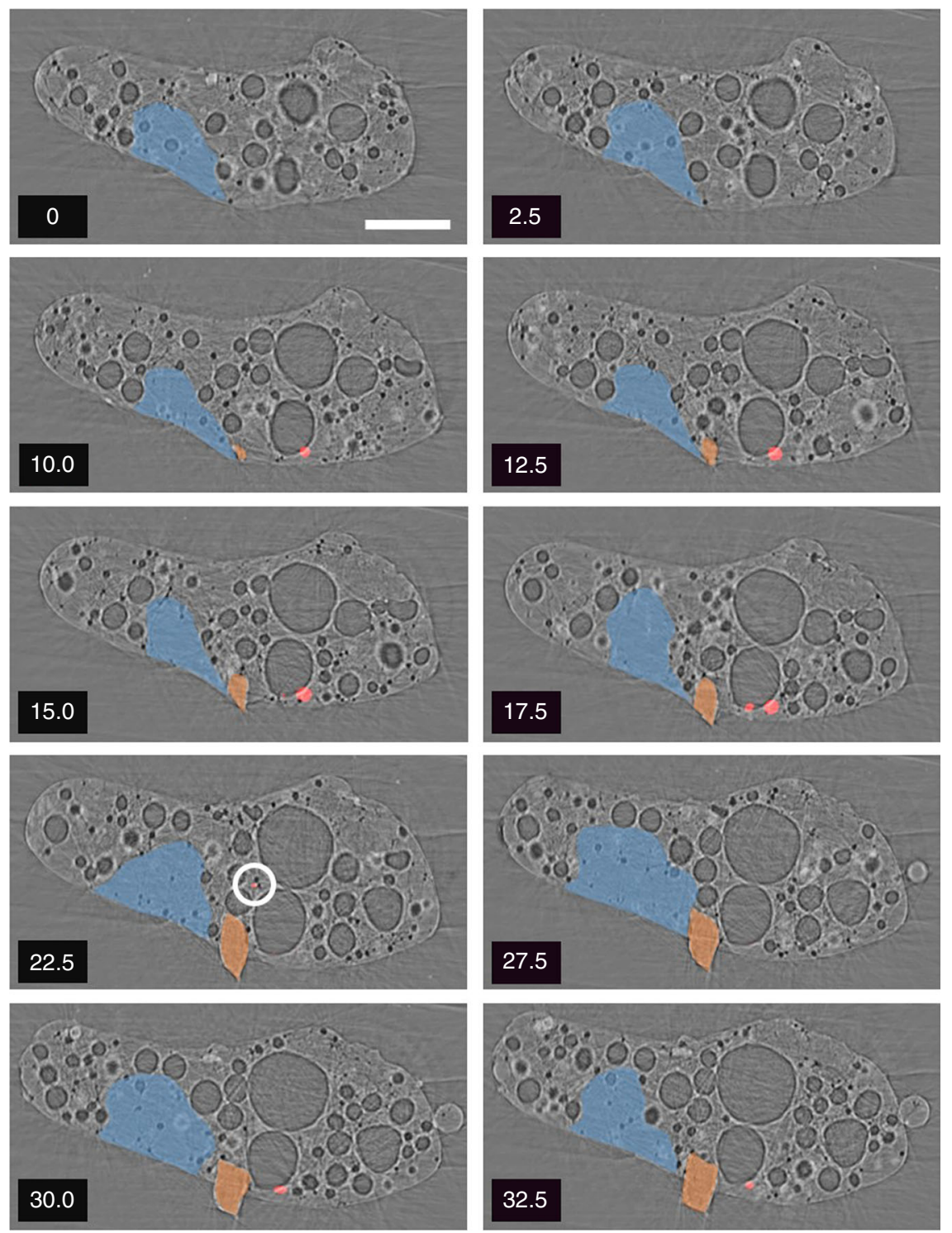

Fig. 1 Combined X-ray tomography and fluorescence cross-sections: sequential longitudinal slices (upwards from the horizontal mid-plane) through the SR- $\mu$-XRT reconstruction, overlain with $U$ composition data (shown in red, and additionally circled in $22.5 \mu \mathrm{m}$ section) as determined via SR- $\mu$-XRF mapping. The location of $\mathrm{Fe}$ (orange) and cement (blue) composition regions are highlighted. The values shown represent the thickness of the tomograph

fragments (such as steel and cement) into the surface of this $\mathrm{Si}-$ based insulation material. The incorporation of these fragments into this softened material resulted in the $\mathrm{U}$ particulate, formerly located around its surface, becoming pushed deeper into the particle towards its center. The existence of the larger number of more peripheral $\mathrm{U}$ particles (located only several microns under the bulk particles surface) can be attributed to the softened state of the Si-based matrix combined with the considerable gas (volatile) over-pressure that existed around the reactor's PCV environment. These conditions served to force the actinide composition material into the particle, having been generated by the earlier $\mathrm{U}$ volatilization/particle formation that followed the integrity compromise and extensive melting of the Unit 1 reactor core $^{13,14}$.

$\mathrm{X}$-ray absorption near edge structure. The results of the analysis performed on two of these inclusions are presented in Fig. 2. The $\mathrm{x}$-ray absorption near-edge structure (XANES) spectra of the particles are characterized by a broad white line that peaks at
$17,176-17,177 \mathrm{eV}$, before smoothly decreasing to a minimum at $17,200 \mathrm{eV}$. This shape has been previously attributed to the U(IV) oxidation state in uranium oxides and glasses, whereas more oxidized forms, such as $\mathrm{U}(\mathrm{V})$ and $\mathrm{U}(\mathrm{VI})$, are characterized by an increasingly asymmetric shape, with an additional shoulder growing around $17,185-17,195 \mathrm{eV}^{26-28}$.

Beam damage, characterized by the reduction of the white line intensity within tens of seconds, has previously been reported for U-containing glasses by Halse ${ }^{29}$. However, these modifications are not accompanied by further changes of the XANES shape relating to a change in the oxidation state upon exposure to the incident $\mathrm{x}$-ray beam. Here, spectra remain unchanged after $15 \mathrm{~min}$ of continued beam exposure and data collectiontherefore discounting any beam-induced oxidation of the particles. While it is possible to obtain XANES data from the U-containing particles, local structure information derived from the succeeding EXAFS region of the spectra is not amenable in this instance, this likely the result of the large size of the incident $\mathrm{x}$-ray beam $(2 \mu \mathrm{m} \times 2 \mu \mathrm{m})$ in comparison to that of the enclosed $\mathrm{U}$ particulate, the subject of analysis. 


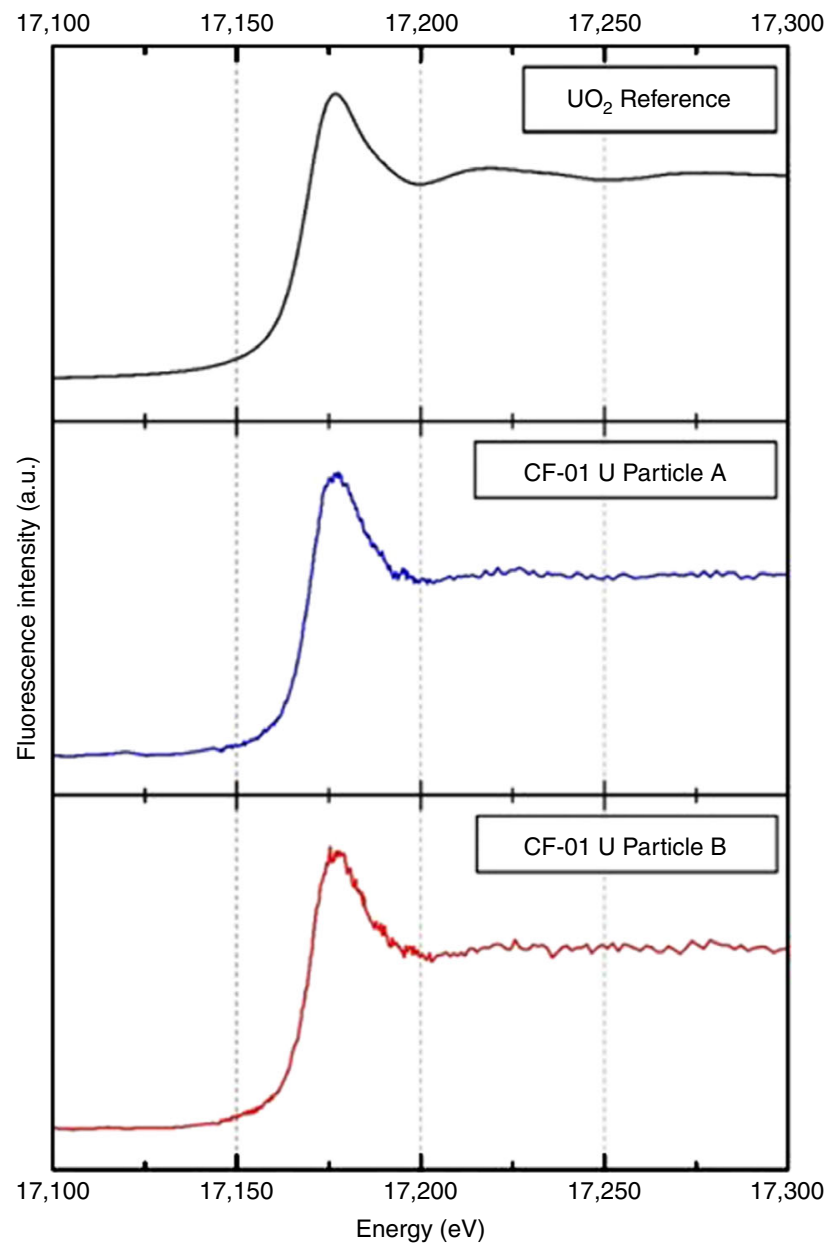

Fig. 2 X-ray absorption edge profiles: SR- $\mu$-XANES fluorescence intensity plots derived from two of the $U$ composition particles contained within the sub-mm Si-based particle, alongside that of a comparison reference $\mathrm{UO}_{2}$ spectra, from $^{44}$

These results confirm the identical structure of the particulate contained within the CF-01 sample to that of standard $\mathrm{UO}_{2}$ nuclear fuel. While highly suggestive of the high melting-point fuel material used extensively in nuclear reactors around the world, $U$ in the (IV) state is also found in numerous naturally occurring primary and secondary uranium ore minerals ${ }^{30}$-with one of the most commonly encountered being that of uraninite $\left(\mathrm{UO}_{2}\right)$. With the Si-based particle's precursor Rockwool ${ }^{\mathrm{Tm}}$ insulation material (derived from a basaltic precursor material) typified by a low $U$ content of $0.2 \mathrm{ppm}^{31}$, and owing also to the spatially heterogeneous (circumferential) distribution of the $U$ particulate, an anthropogenic provenance is most likely. It is therefore also through the application of SIMS to derive true isotopic ratios that a natural occurrence can be entirely excluded.

Secondary ion mass spectrometry. With SR- $\mu$-XANES analysis showing the $\mathrm{U}$ to exist in the $\mathrm{U}(\mathrm{IV})$ oxidation state $\left(\right.$ as $\left.\mathrm{UO}_{2}\right)$ and, therefore, the composition of either nuclear fuel or naturally occurring mineral material, the isotopic results provided by SIMS analysis serves as the critical indicator in ascribing it definitively to a reactor source-and to Unit 1 at the FDNPP. The result of SIMS compositional mapping over the vertical cut face produced by ion beam depth profiling is shown in Fig. 3. From this image, a micron-scale particle at $238 \mathrm{amu}$ (marked in red) is observed on the vertical face of the milled region, as expected following earlier XRF elemental mapping and ion beam sample preparation. Also

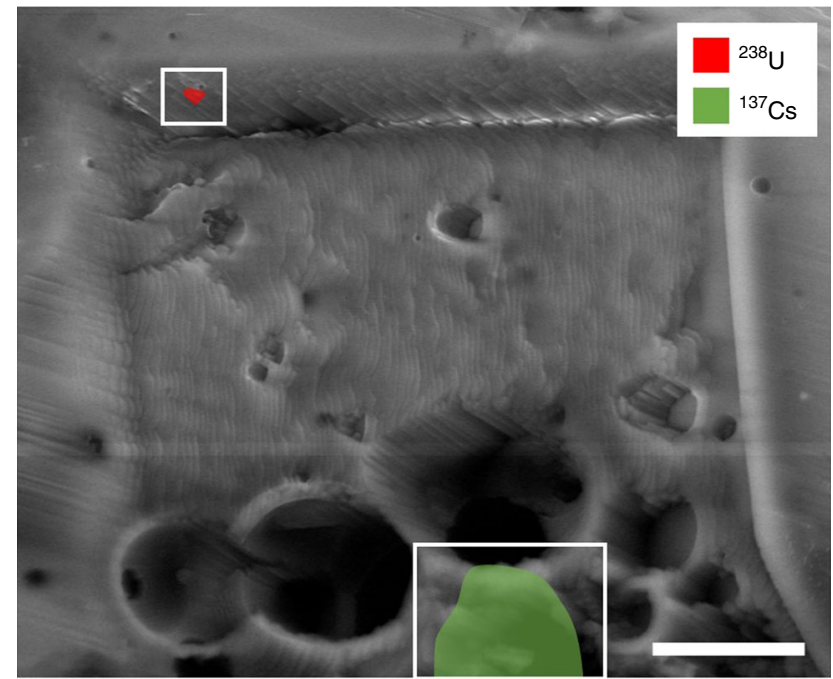

Fig. 3 SIMS depth-profile compositional mapping: compositional mapping results $\left(238 \mathrm{U}\right.$ and ${ }^{137} \mathrm{Cs}$ ) overlain onto the trench produced following SIMS depth-profiling into FIB-cut face. Scale bar $=10 \mu \mathrm{m}$

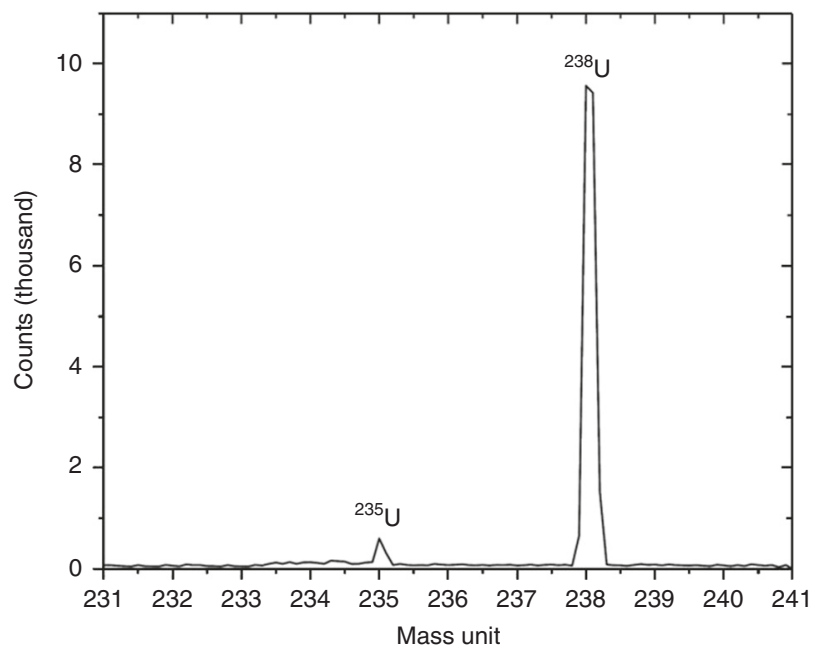

Fig. 4 Uranium mass spectra: mass spectra between 231 and 241 amu obtained from the $U$ particle contained within the CF-01 bulk particle (as identified in Fig. 3)

apparent is a discrete region of ca. $10 \mu \mathrm{m}$ diameter at the base of the trench, with a mass of $137 \mathrm{amu}$-attributed to the fission product ${ }^{137} \mathrm{Cs}$.

The mass spectra (between 231 and $241 \mathrm{amu}$ ) of this $U$ particle is shown in Fig. 4. From this, the discernible peaks are at 238 and $235 \mathrm{amu}$. The ratio of integral peaks gives an atomic ratio $\left({ }^{235} \mathrm{U} /\right.$ $\left.{ }^{238} \mathrm{U}\right)$ of $0.0354 \pm 0.0015\left(3.54 \pm 0.15 \mathrm{wt} \%{ }^{235} \mathrm{U}\right)$. This elevated ${ }^{235} \mathrm{U}$ concentration above the globally averaged natural abundance of $0.72 \%^{32}$ clearly identifies this material as being anthropogenic. The absence of other masses (e.g. 234, 236, 239, and $240 \mathrm{amu}$ ) within the spectra (Fig. 4) could be attributed to the lack of fuel burn-up of this component of fuel material, and therefore transmutation of the parent isotopes that would result in the ingrowth of these additional mass species (N.B. the burnup of the fuel in reactor Unit 1 averaged a considerable 39.5 to 45 GWD/t). The poor mass-sensitivity of SIMS at these higher massunits could equally be invoked to represent the detection of only these two masses $\left({ }^{235} \mathrm{U}\right.$ and $\left.{ }^{238} \mathrm{U}\right)$, and not the lower concentrations of the other actinide species that may exist. With 
higher-sensitivity instrumentation, mass peaks at both 234 and $236 \mathrm{amu}$ would be expected-lending additional support to the materials reactor provenance.

While the Cs (137 amu) region is characteristically rounded in its form, the $U$ fragment is significantly more angular. This angularity supports the theory that a loss of structural integrity occurred in the fuel assemblies following their extensive melting in the LOCI and an ensuing fragmentation/particle generation occurred during the subsequent reactor building hydrogen explosion ${ }^{13-15}$.

In contrast, the more spatially diffuse distribution exhibited by the Cs (Fig. 4) invokes a differing provenance to that of U. This can be ascribed to the known difference in the melting point/ volatilization temperature of the two elements ${ }^{33}$. At the time of the accident, the highly volatile fission product (Cs), as well as other similarly volatile elements, would have existed in a gaseous state at a considerable over-pressure within the reactor Unit 1 pressure vessel. This gas was resultantly incorporated into the partially molten Si-based material in the diffuse manner observed.

As the two primary radioisotopes of cesium $\left({ }^{134} \mathrm{Cs}\right.$ and ${ }^{137} \mathrm{Cs}$ ) decay to stable isotopes of barium $\left({ }^{134} \mathrm{Ba}\right.$ and ${ }^{137} \mathrm{Ba}$, respectively), an inventory of $\mathrm{Ba}$ would exist associated with this Cs-rich region as a result of radiogenic ingrowth. The secondary ion mass spectra (using a positive voltage bias) over the 135-138 amu mass window is shown in Fig. 5. This spectra comprises two mass peaks; 135 and $137 \mathrm{amu}$. The mass peak at $135 \mathrm{amu}$ is likely to represent the sole contribution from ${ }^{135} \mathrm{Cs}$, a long-lived fission product $\left(t_{1 / 2}=2.3 \times 10^{6}\right.$ years $)$. In contrast, the mass peak at 137 amu is a combination of ${ }^{137} \mathrm{Cs}$, alongside a minor contribution from radiogenic $\mathrm{Ba}$. As well as this ingrown $\mathrm{Ba}$, a further source of the element is that which arises from the naturally occurring $\mathrm{Ba}$. However, such a contribution from pre-existing (natural) Ba in this instance is precluded because of the absence of a mass peak at $138 \mathrm{amu}$-the primary mass of $\mathrm{Ba}$, therefore suggesting that this $\mathrm{Ba}$ results entirely from radiogenic ingrowth. The small contribution at mass $136 \mathrm{amu}$ is the likely result of the decay of the short-lived ${ }^{136} \mathrm{Cs}\left(t_{1 / 2}=13.16\right.$ days $)$ into the stable ${ }^{136} \mathrm{Ba}$.

Source attribution. With the likely anthropogenic provenance of the $\mathrm{U}$ particulate inclusions shown through combined SR- $\mu$ XANES and SIMS analysis, a comparison of the ${ }^{235} \mathrm{U}$ content of this $\mathrm{U}$ particle (CF-01) is shown alongside the published values

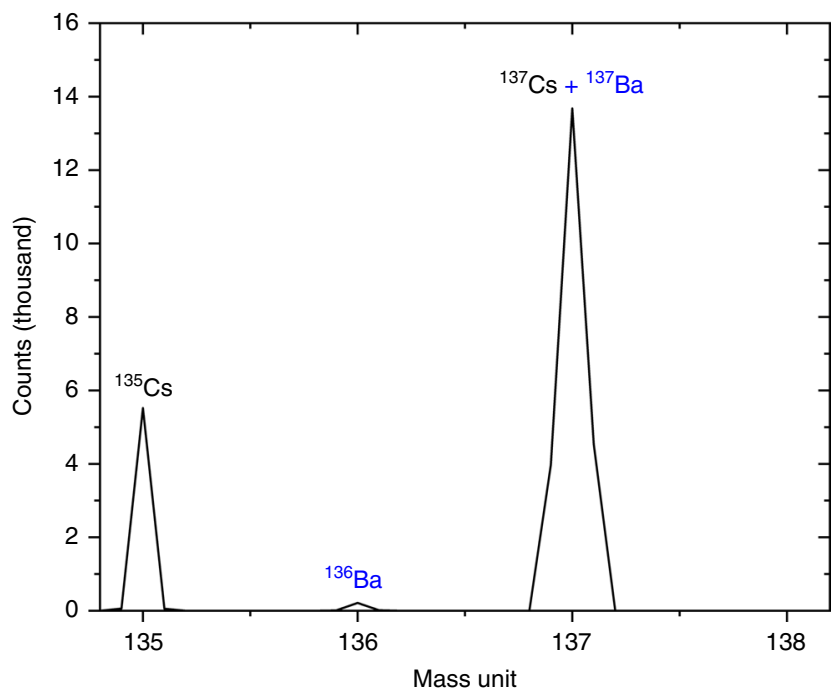

Fig. $5 \mathrm{Cs}$ and Ba mass spectra: SIMS mass spectra (positive bias) between 135 and 138 amu, derived from the Cs-rich region evidenced to exist within the CF-01 bulk particle (identified in Fig. 3)

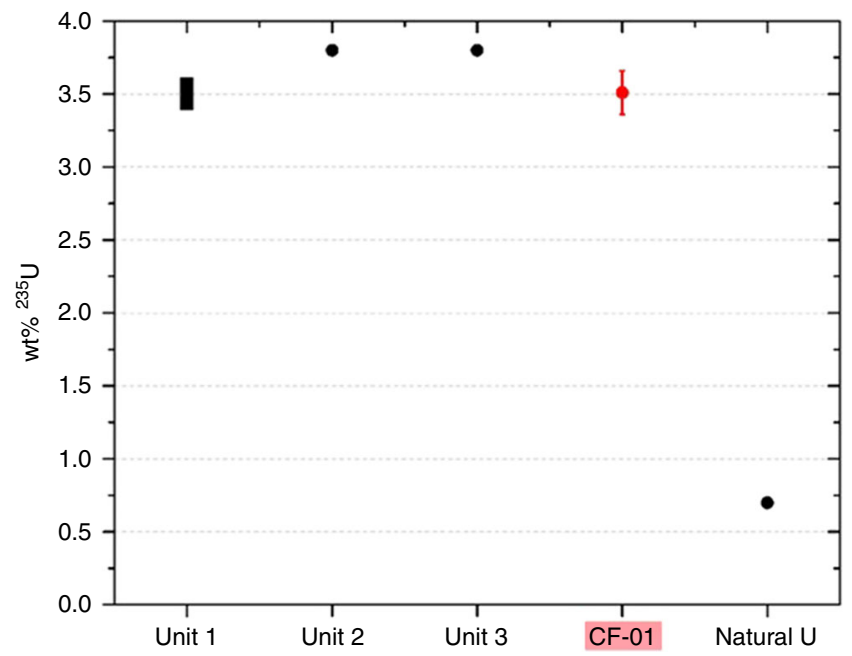

Fig. 6 Core inventory comparison: comparison of the $235 \cup$ wt $\%( \pm 2 \sigma)$ measured in this work via SIMS (CF-01) with operational wt\% $235 U$ values published by the sites operator, TEPCO 25

for reactor Units 1, 2 and 3 (alongside that of natural U) in Fig. 6. Having been attributed in earlier works to reactor Unit 1 through its ${ }^{134} \mathrm{Cs} /{ }^{137} \mathrm{Cs}$ activity ratio ${ }^{16}$, the atomic ratio ${ }^{235} \mathrm{U} /{ }^{238} \mathrm{U}$ content in this single $U$ particle further supports this provenancing. In contrast to reactor Units 2 and 3 which, as shown in Fig. 6, were operating with higher $\mathrm{UO}_{2}$ fuel enrichments of $3.8 \mathrm{wt} \%{ }^{235} \mathrm{U}$, Unit 1 was operating with enrichments between 3.4 and $3.6 \mathrm{wt} \%$ ${ }^{235} \mathrm{U}$. The $3.54 \pm 0.15 \mathrm{wt} \%{ }^{235} \mathrm{U} \quad\left(0.0354 \pm 0.0015 \quad{ }^{235} \mathrm{U} /{ }^{238} \mathrm{U}\right.$ atomic ratio) determined for the (CF-01) particle reported here is, therefore, consistent with the published core loading values for reactor Unit 1.

\section{Discussion}

We detail the first multi-technique evaluation on U-containing material sourced from the reactor building hydrogen explosion that occurred in Unit 1 of the FDNPP. The combined use of advanced synchrotron-based $\mathrm{x}$-ray analysis techniques alongside the isotopic analysis afforded by SIMS, shows that the U inclusions were isotopically enriched in ${ }^{235} \mathrm{U}$. Combining this result with the particles radiocesium ratio, we definitively attribute the sub-mm ejecta particle as having originated from reactor Unit 1 . Any suggested natural provenance of this $U$ (arising from species initially contained within the source Rockwool ${ }^{\mathrm{Tm}}$ insulation material) can, therefore, be disregarded. Embedded within the glassy Si-based bulk particle (akin to vitrified waste ${ }^{34}$ ) and considering the insoluble nature of the U(IV) oxide material, a longterm environmental stability is implied-with a very-limited risk to health unless the bulk material were to fragment (e.g. through mechanical attrition). Despite any potential inherent toxicity of $U$ being suppressed with the material in its current form ${ }^{35,36}$, considerations must be made to account for the likely existence of other (equally, if not more, toxic) actinide species (for example $\mathrm{Pu}$ ), that may also exist within such Unit 1 ejecta material ${ }^{37}$. While the materials toxicity may not currently be of significance, this work has highlighted the extent of reactor core and containment failure at Unit 1 and the resulting implications for the long-term decommissioning strategy of the reactor core that is set to commence shortly. Although an inventory of other (longerlived) fission product and activation species were released and could be identified utilizing the methods described in this work, this study has chosen to focus solely on source attribution using combined $\mathrm{U}$ and $\mathrm{Cs}$ analysis. Future work will utilize other 
elements and isotopic ratios to further constrain the materials provenance and conditions/environment of formation.

\section{Methods}

Sample collection and preparation. Bulk $(\sim 100 \mathrm{~g})$ exposed samples, identified to exhibit elevated levels of radioactivity when scanned using a hand-held Geiger-Müller instrument, were collected in October 2014 within the highly contaminated Restricted Zone and a site formerly attributed to have been contaminated by reactor Unit $1^{11,12}$. This material was obtained from the ground (as dust samples) at $37.4379^{\circ} \mathrm{N}, 141.0222^{\circ} \mathrm{E}, 2 \mathrm{~km}$ NNW from the center of FDNPP. To extract the particles from the surrounding organic sediment, a multi-stage autoradiography, division, and extraction process was employed ${ }^{38}$. After removal, each of the sub-mm particles was placed onto a piece of adhesive Kapton ${ }^{\text {mi }}$ film. An initial quantification of each particle was then performed using SEM with associated energy dispersive spectroscopy (EDS) and gamma-ray spectrometry using a high-volume detector, the results of which are discussed elsewhere ${ }^{24}$. Greater than 20 similar sub-mm particles were extracted from the sediment and found upon here representative of the average size/volume, with typical surface composition and internal structure

To enable SR analysis of this representative particle, it was further enclosed within additional layers of $\mathrm{x}$-ray transparent Kapton ${ }^{\text {"xt }}$ film for the multiple synchrotron-based techniques. A corner of the Kapton ${ }^{\text {mi }}$ envelope was glued onto a $1 \mathrm{~cm}$ aluminum support pin, which was then attached to a magnetic base for its installation and movement on the different synchrotron beamline stages. During this work, a representative CF-01 particle was used-with dimensions; $450 \times 280 \times$ $250 \mu \mathrm{m}$.

Synchrotron radiation analysis. SR analysis of the particle was performed on the I13-1 (coherence imaging) and the I18 (micro-focus spectroscopy) beamlines at the Diamond Light Source (DLS; Harwell, UK) ${ }^{39}$. Both three-dimensional SR- $\mu$-XRF and SR- $\mu$-XRT of the particle were first performed on the I13-1 beamline, prior to SR- $\mu$-XAS on the I18 beamline. With a distance of $250 \mathrm{~m}$ between the insertion device (canted undulator) and the sample, the I13-1 beamline utilizes the highly coherent $\mathrm{x}$-rays produced by the experimental optics, with an energy range of 4-23 $\mathrm{keV}$ (a maximum of $19 \mathrm{keV}$ was used in this work) and typical flux of $10^{9}$ photons/ s. Despite being located closer to the insertion device, the I18 beamline uses a similar optical setup to the longer I13-1 beamline-with a comparable energy range of 3-22 keV, tunable in $0.5 \mathrm{eV}$ increments using a cryogenically cooled Si-111 monochromator.

Using the I13-1 beamline at the Diamond Light Source ${ }^{40}$, the particle was studied using both $\mu$-XRT, and 3D $\mu$-XRF. For the XRT acquisition, the sample was illuminated with a $19 \mathrm{keV}$ collimated X-ray beam. The particle was rotated over a range of $180^{\circ}$ in steps of $0.1^{\circ}$. The projections were acquired with an optical microscope coupled to a $26 \mu \mathrm{m}$-thick GGG:Eu scintillator. The total optical magnification of $\times 20$ provided a pixel size of $0.45 \mu \mathrm{m}$. For the 3D XRF analysis, the $\mathrm{X}$-ray beam was formed through a $5 \mu \mathrm{m}$ pinhole positioned upstream of the sample. At each angle of the 3D XRF, the sample was scanned with respect to the beam in a raster grid of $40 \times 20$ steps with a step size of $2.5 \mu \mathrm{m}$, giving a field of view of $100 \mu \mathrm{m} \times 50 \mu \mathrm{m}$. At each scan position, the X-ray fluorescence spectrum was acquired using a single channel silicon drift Vortex ${ }^{\circ} \mathrm{X}$-ray detector placed in the plane of the sample, normal to the direction of propagation of the beam. The sample was rotated over a range of $180^{\circ}$ in steps of $4.5^{\circ}$

From the series of fluorescence projections, the three-dimensional volume for each element was reconstructed using the ordered-subset penalized maximumlikelihood algorithm, with weighted linear and quadratic penalty algorithms in the TomoPy framework ${ }^{41}$. An iterative algorithm to correct for the degree of sample self-absorption that occurred was also employed for the tomography results. The reconstructed overlay images were produced using ImageJ and Python software platforms.

For the I18 SR- $\mu$-XANES analysis, an identical particle setup was used. Prior to the analysis, an initial two-dimensional SR- $\mu$-XRF scan was made of the particle at $21 \mathrm{keV}$ (full beam size flux at $10 \mathrm{keV}=10^{12}$ photons/s), with the sample similarly rastered through the incident X-ray beam in $2 \mu \mathrm{m}$ steps (resulting in a $2 \mu \mathrm{m}$ spatial (pixel) resolution) to re-establish the positions of the high-density (U-containing) particles. Once these positions were located, SR- $\mu$-XANES was performed. For this analysis, the stage position was maintained whilst the incident beam energy was varied-tuned by the monochromator over the $\mathrm{U}-\mathrm{L}_{\text {III }}$ edge $(17,166 \mathrm{eV})$, at various energy steps ( $5 \mathrm{eV}$ from 17,025 to $17,140 \mathrm{eV}, 0.5 \mathrm{eV}$ from 17,140 to $17,205 \mathrm{eV}, 1 \mathrm{eV}$ from 17,205 to $17,275 \mathrm{eV}, 2 \mathrm{eV}$ from 17,275 to $17,400 \mathrm{eV}$ and finally in $2.5 \mathrm{eV}$ steps from 17,400 to $17,510 \mathrm{eV}$ ). Three repetitions of each scan were made in each instance to improve the resulting signal-to-noise ratio in the data. The SR- $\mu$ XANES data was analyzed using the Demeter (ATHENA/ARTEMIS) suite of software ${ }^{42}$-based on the open-source IFEFFIT code ${ }^{43}$. Calibration of the I18 monochromator (with an inherent stability of $\pm 0.05 \mathrm{eV}$ per day) before and after the analysis was undertaken using a series of material standards with characteristic emission energies. The reference material standard for the U- $\mathrm{L}_{\mathrm{III}}$ edge comparison was sourced from the International X-ray Absorption Society Database (Reference: atm-1c-glass reference 13 edge $)^{44}$.
Secondary ion mass spectrometry. Having determined the locations at which $U$ composition particulate was located inside the parent particle, isotopic analysis was performed using magnetic sector (MS) SIMS. The MS-SIMS system used in this study was a custom-built instrument utilizing a primary $\mathrm{Ga}^{+}$ion beam to sputter the samples surface before filtering and measuring the resulting secondary ion species across the 0-300 amu mass range. However, as the U-containing particulate was observed to exist several microns below the surface of the sample, FIB milling (using an FEI Helios NanoLab F600i dual FIB-SEM system) was conducted to expose the $\mathrm{U}$ particle and produce a cut face $\sim 80 \times 80 \mu \mathrm{m}$. Prior to this preparation (and subsequent SIMS analysis), the particle was carefully removed from its Kapton $^{\text {tw }}$ film envelope and placed onto a low elemental background electrically conductive carbon Spectro Tab (TED PELLA Inc.) before being sputter-coated (Edwards Vacuum Scancoat Six) with a $2 \mathrm{~nm}$ film of conductive Au. Progressively decreasing $\mathrm{Ga}^{+}$ion beam cutting energies (reduced from $16 \mathrm{nA}$ to $90 \mathrm{pA}$ ) were used to obtain a surface free from the artefacts of the milling process.

With a flat surface produced on the highly textured CF-01 particle to a depth just above the location of the $\mathrm{U}$ composition particle, depth profiling was first used to locate the edge of the actinide fragment. A $\times 5000$ magnification was usedproducing a $40 \times 40 \mu \mathrm{m}$ trench (alongside a dwell-time of $2500 \mathrm{~ms}$ for each of the six mass units measured) to mill to a depth of $10 \mu \mathrm{m}$. A rapid-scan ion map (two raster frames) was then performed on the cut vertical surface, where the $U$ particle was observed to exist (using the same parameters as those employed for depth profiling) to exactly locate the contained particle. Finally, a spectrum over the $U$ mass window (231-241 amu, with $0.05 \mathrm{amu}$ steps and $5000 \mathrm{~ms}$ dwell-time) was performed to evaluate the specific isotopic composition of the $\mathrm{U}$ inclusion. This mass range was swept three times to enhance the signal quality and reduce spurious noise within the data.

\section{Data availability}

The raw (unprocessed) data that supports the findings of this study are available from Mendeley Data, with the https://doi.org/10.17632/46db2h9kwr.1

Received: 27 June 2018 Accepted: 11 June 2019

Published online: 26 June 2019

\section{References}

1. Abe, Y. et al. Detection of uranium and chemical state analysis of individual radioactive microparticles emitted from the Fukushima nuclear accident using multiple synchrotron radiation X-ray analyses. Anal. Chem. 86, 8521-8525 (2014).

2. Adachi, K., Kajino, M., Zaizen, Y. \& Igarashi, Y. Emission of spherical cesiumbearing particles from an early stage of the Fukushima nuclear accident. Sci. Rep. 3, 5 (2013).

3. Imoto, J. et al. Isotopic signature and nano-texture of cesium-rich microparticles: release of uranium and fission products from the Fukushima Daiichi Nuclear Power Plant. Sci. Rep. 7, 12 (2017).

4. Yamaguchi, N. et al. Internal structure of cesium-bearing radioactive microparticles released from Fukushima nuclear power plant. Sci. Rep. 6, 6 (2016).

5. Martin, P. G., Satou, Y., Griffiths, I., Richards, D. \& Scott, T. Analysis of external surface irregularities on Fukushima-derived fallout particles. Front. Energy Res. 5, 9 (2017).

6. Ono, T. et al. Investigation of the chemical characteristics of individual radioactive microparticles emitted from reactor 1 by the Fukushima Daiichi Nuclear Power Plant accident by using multiple synchrotron radiation X-ray analyses. Bunseki Kagaku 66, 251-261 (2017).

7. Croff, A. G. Origen2: a versatile computer code for calculating the nuclide compositions and characteristics of nuclear materials. Nucl. Technol. 62, 335-352 (1983).

8. Nishihara, K., Iwamoto, H. \& Suyama, K. Estimation of Fuel Compositions in Fukushima-Daiichi Nuclear Power Plant. JAEA (Ibaraki) 2012-2018 (2012).

9. CRC Press. CRC Handbook of Chemistry and Physics-Table of Isotopes (CRC Press, Boca Raton, FL, 2015).

10. Zheng, J. et al. $135 \mathrm{Cs} / 137 \mathrm{Cs}$ isotopic ratio as a new tracer of radiocesium released from the Fukushima Nuclear Accident. Environ. Sci. Technol. 48, 5433-5438 (2014).

11. Nishizawa, Y., Yoshida, M., Sanada, Y. \& Torii, T. Distribution of the 134Cs/ 137Cs ratio around the Fukushima Daiichi Nuclear Power Plant using an unmanned helicopter radiation monitoring system. J. Nucl. Sci. Technol. 53, 1-7 (2015).

12. Chino, M. et al. Utilization of $134 \mathrm{Cs} / 137 \mathrm{Cs}$ in the environment to identify the reactor units that caused atmospheric releases during the Fukushima Daiichi accident. Sci. Rep. 6, 14 (2016).

13. IAEA. Technical Vol. 1 of 5: Description and Context of the Accident. In The Fukushima Daiichi Accident 238 (IAEA, 2015). http://www-pub.iaea.org/ MTCD/Publications/PDF/AdditionalVolumes/P1710/Pub1710-TV1-Web.pdf. 14. TEPCO. Fukushima Nuclear Accident Analysis Report 2012. (2012). 
15. World Nuclear Association. The Fukushima Daiichi Accident. http://www. world-nuclear.org/focus/fukushima/fukushima-accident.aspx. Accessed 1 Aug 2017 (2017).

16. Satou, Y. Study of Relationship between Deposition of Radioactive Materials and Radioactive Particles in the Difficult-to-return Zone Caused by the Fukushima Dai-ichi Nuclear Power Plant accident (University of Tsukuba, 2016).

17. Kogure, T. et al. Constituent elements and their distribution in the radioactive Cs-bearing silicate glass microparticles released from Fukushima nuclear plant. Microscopy 65, 451-459 (2016).

18. Furuki, G. et al. Caesium-rich micro-particles: a window into the meltdown events at the Fukushima Daiichi Nuclear Power Plant. Sci. Rep. 7, 10 (2017).

19. Wu, J., Hu, X., Ma, J., Zhang, C. \& Mojia, S. Analysis of ground deposition of radionuclides under different wind fields from the Fukushima Daiichi accident. Nat. Hazards 1-12 (2017). https://doi.org/10.1007/s11069-017-2777-7

20. TEPCO. Measurement Data at Fukushima Daiichi Nuclear Power Station. http://www.tepco.co.jp/nu/fukushima-np/f1/data/2011/index-j.html. Accessed 2 Aug 2017 (2011).

21. Tsuruta, H., Oura, Y., Ebihara, M., Ohara, T. \& Nakajima, T. First retrieval of hourly atmospheric radionuclides just after the Fukushima accident by analyzing filter-tapes of operational air pollution monitoring stations. Sci. Rep. 4, 10 (2014).

22. Snow, M. S., Snyder, D. C. \& Delmore, J. E. Fukushima Daiichi reactor source term attribution using cesium isotope ratios from contaminated environmental samples. Rapid Commun. Mass Spectrom. 30, 523-532 (2016).

23. METI. Areas to which Evacuation Orders have been issued. 1 http://www.meti. go.jp/english/earthquake/nuclear/roadmap/pdf/150905MapOfAreas.pdf. Accessed 13 May 2016 (2015).

24. Satou, Y. et al. Analysis of two forms of radioactive particles emitted during the early stages of the Fukushima Dai-ichi Nuclear Power Station accident. Geochem. J. 52, 137-143 (2018).

25. TEPCO. Fukushima Daiichi NPS-Information Portal. https://fdada.info/en/ home2/accident2/specification2/. Accessed 16 December 2017 (2013).

26. Kosog, B., La Pierre, H. S., Denecke, M. A., Heinemann, F. W. \& Meyer, K. Oxidation state delineation via U L III-edge XANES in a series of isostructural uranium coordination complexes. Inorg. Chem. 51, 7940-7944 (2012).

27. Petiau, J. et al. Delocalized versus localized unoccupied $5 \mathrm{f}$ states and the uranium site structure in uranium oxides and glasses probed by $\mathrm{x}$-rayabsorption near-edge structure. Phys. Rev. B 34, 7350-7361 (1986).

28. Stefanovsky, S. V., Stefanovskaya, O. I., Murzin, V. Y., Shiryaev, A. A. \& Myasoedov, B. F. Oxidation state and coordination environment of uranium in sodium iron aluminophosphate glasses. Dokl. Phys. Chem. 468, 76-79 (2016).

29. Halse, H. R. Using Synchrotron Radiation to Determine the Oxidation State of Uranium in Magmas (Imperial College London, 2014).

30. Mindat.org. Mineralogy Database-Mineral Collecting, Localities, Mineral Photos and Data. https://www.mindat.org/. Accessed 20 October 2017 (2017).

31. Morgan, J. W. \& Lovering, J. F. Uranium and thorium abundances in the basalt cored in mohole project (Guadalupe site). J. Geophys. Res. 70, 4724-4725 (1965).

32. Bohlke, J. K. Isotopic compositions of the elements, 2001. J. Phys. Chem. Ref. Data 34, 57-67 (2001).

33. Pontillon, Y. \& Ducros, G. Behaviour of fission products under severe PWR accident conditions. The VERCORS experimental programma-Part 2: Release and transport of fission gases and volatile products. Nucl. Eng. Des. 240, 1853-1866 (2010).

34. Burns, W. G., Hughes, A. E., Marples, J. A. C., Nelson, R. S. \& Stoneham, A. M. Effects of radiation on the leach rates of vitrified radioactive waste. J. Nucl. Mater. 285, 130-132 (1982).

35. Timbrell, J. Principles of Biochemical Toxicology (CRC Press, 1999). https://books.google.co.uk/books?hl=en\&lr=\&id=ElriaDL4QcEC\&oi= fnd \&pg $=$ PT 10\&dq $=$ Principles + of + Biochemical + Toxicology. + Timbrell, + John\&ots $=0$ olcfAwIR4\&sig $=$ XqL6H9DiPNv7RNXe3yD88pcusRM.

36. Runde, W. The chemical interactions of actinides in the environment. Los Alamos Sci. 26, 392-411 (2000).

37. Wilson, P. D. The Nuclear Fuel Cycle: From Ore to Wastes. (Oxford University Press, 1996). https://inis.iaea.org/search/search.aspx?orig_q=RN:28071286.

38. Satou, Y., Sueki, K., Sasa, K., Adachi, K. \& Igarashi, Y. First successful isolation of radioactive particles from soil near the Fukushima Daiichi Nuclear Power Plant. Anthropocene 14, 71-76 (2016).
39. Diamond Light Source Ltd. How Diamond Works-Diamond Light Source. http://www.diamond.ac.uk/Home/About/How-Diamond-Works.html. Accessed 21 Sept 2017 (2017).

40. Rau, C. Imaging with coherent synchrotron radiation: X-ray imaging and coherence beamline (I13) at diamond light source. Synchrotron Radiat. News 30, 19-25 (2017).

41. Gursoy, D., De Carlo, F., Xiao, X. \& Jacobsen, C. TomoPy: a framework for the analysis of synchrotron tomographic data. J. Synchrotron Radiat. 21, 1188-1193 (2014).

42. Ravel, B. \& Newville, M. ATHENA, ARTEMIS, HEPHAESTUS: data analysis for X-ray absorption spectroscopy using IFEFFIT. J. Synchrotron Radiat. 12, 537-541 (2005).

43. Newville, M. IFEFFIT: interactive XAFS analysis and FEFF fitting. J. Synchrotron Radiat. 8, 322-324 (2001).

44. International X-ray Absorption Society. IXAS XAFS Database. http://ixs.iit. edu/database/. Accessed 30 Jan 2018 (2018).

\section{Acknowledgements}

This work was supported by funding provided by the Daiwa Anglo-Japanese Foundation (Grant Reference: 11424), the Great Britain Sasakawa Foundation (Grant Reference: 5223), and the EPSRC (Reference: EP/S020659/1). The authors wish to thank staff at the Diamond Light Source synchrotron for their assistance during the experiments performed at the facility that have contributed to the results presented within this work (Experiment References: MT16701/MT16702/SP18186). The SEM used to conduct imaging and EDS analysis was purchased following funding from the EPSRC (Reference: EP/K040340/1). Y.S. would like to acknowledge Dr. Haruka Minowa (Jikei University), Dr's. Hideki Yoshikawa and Shingeo Nakama (Environmental Safety Center, JAEA) for their assistance during sample collection, as well as Prof. Keisuke Sueki and Mr. Kazuki Matsuo (University of Tsukuba) for their assistance with both sample collection and initial material analysis.

\section{Author contributions}

All authors contributed to the experimental work undertaken as part of this article, with the manuscript written by P.G.M., S.C., D.J.B., C.R., D.A.R., T.B.S. and K.R.H. Processing of $\mathrm{x}$-ray absorption spectroscopy data was undertaken by M.L. and J.F.M., with assistance during collection from C.P.J. and I.A.X.Y. Particle extraction was performed by Y.S. All authors have given approval to the final version of the manuscript.

\section{Additional information}

Competing interests: The authors declare no competing interests.

Reprints and permission information is available online at http://npg.nature.com/ reprintsandpermissions/

Peer review information: Nature Communications thanks Rodney Ewing, and the other, anonymous, reviewer(s) for their contribution to the peer review of this work.

Publisher's note: Springer Nature remains neutral with regard to jurisdictional claims in published maps and institutional affiliations.

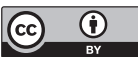

Open Access This article is licensed under a Creative Commons Attribution 4.0 International License, which permits use, sharing, adaptation, distribution and reproduction in any medium or format, as long as you give appropriate credit to the original author(s) and the source, provide a link to the Creative Commons license, and indicate if changes were made. The images or other third party material in this article are included in the article's Creative Commons license, unless indicated otherwise in a credit line to the material. If material is not included in the article's Creative Commons license and your intended use is not permitted by statutory regulation or exceeds the permitted use, you will need to obtain permission directly from the copyright holder. To view a copy of this license, visit http://creativecommons.org/ licenses/by/4.0/.

(C) The Author(s) 2019 